\title{
俯冲陆壳内部的拆离和超高压岩石的多板片差异折返: 以大别-苏鲁造山带为例
}

\author{
刘贻灿, 李曙光 \\ 中国科学院壳幔物质与环境重点实验室, 中国科学技术大学地球和空间科学学院, 合肥 230026 \\ E-mail: 1iuyc@ustc.edu.cn, 1sg@ustc.edu.cn
}

2008-02-04 收稿, 2008-06-17 接受

中国科学院知识创新工程重要方向性项目(批准号: KZCX2-YW-131)和国家自然科学基金项目(批准号: 40572035, 40634023, 40773013)资助

\begin{abstract}
摘要 对国内外学者关于大陆碰撞过程中深俯冲陆壳的折返机制模型进行了简要评述, 并以大 别-苏鲁造山带为例, 对大陆碰撞过程中俯冲陆壳内部在不同深度发生多层次地壳拆离解耦并呈 多板片差异折返的关键证据进行概括. 这些证据包括: (1) 大别-苏鲁超高压带北侧分布的具有华 南陆壳特征, 部分经历过三叠纪变质的浅变质岩片, 它们显示了陆壳俯冲开始阶段其上部地壳与 下部基底岩石的解耦; (2) 大别-苏鲁高压-超高压带均由若干高压-超高压岩片组成, 这些岩片由 南至北变质程度逐步加深、峰期和退变质时代逐步变年轻; (3) 苏北大陆科学钻探揭示了超高压变 质带在垂向上也是由若干岩片组成，上部岩片具有高放射成因 $\mathrm{Pb}$, 下部岩片具有低放射成因 $\mathrm{Pb}$, 反映了俯冲陆壳在不同深度的解耦和折返. 俯冲陆壳内部的拆离解耦和差异折返, 主要是由于大 陆地壳上、下不同部位岩石组成的差异导致的力学性质差异和壳内古断层带作为流体通道而被弱 化的结果. 该模型的建立, 突破了陆壳整体俯冲与整体折返的传统模式, 揭示了陆壳俯冲与洋壳 俯冲的主要区别. 在此基础之上, 提出了有待于进一步研究的若干重要科学问题.
\end{abstract}

关键词

大陆俯冲

超高压变质

板片折返

地壳拆离

薄皮构造

大别-苏鲁
柯石英 ${ }^{[1 ~ 5]}$ 和金刚石 ${ }^{[6,7]}$ 等超高压变质矿物的相 继发现, 已证明巨量陆壳岩石能俯冲到地幔深度. 因 此近 20 年来, 超高压岩石的形成与折返机制, 一直 是大陆动力学的研究热点. 其中, 超高压岩石的折返 机制是长期争议的焦点, 并且, 已提出多种解释模型, 如, 陆内逆冲及伴随侵蚀模式 ${ }^{[8,9]}$ 、挤出-伸展模式 [10 13] 、浮力驱动模式 ${ }^{[14]}$ 、浮力-楔入-热穹隆模式 ${ }^{[15]}$ 、 角流及浮力联合模式 $[16]$ 平行于造山带的挤出及伴随 减薄模式 $[17.18]$ 、连续俯冲-折返-热穹隆模式 ${ }^{[19]}$ 等等. 所有这些模式都是假定整个俯冲陆壳与下伏岩石圈 地幔发生拆离解耦并整体折返(如, 文献[17, 20 22]).

与此相反, 近年来中国部分学者根据对大别-苏 鲁造山带的研究成果, 提出俯冲陆壳内部曾发生多 层次拆离解耦并呈多板片差异折返的模型 ${ }^{[23 ~ 28]}$. 已 有研究表明, 俯冲陆壳不仅在深部发生拆离解耦 [23 28], 而且在俯冲初期即榴辉岩相变质前在浅部
不同深度也发生了地壳拆离并逆冲折返 ${ }^{[29 ~ 34]}$. 因此, 深俯冲陆壳是整体折返, 还是内部拆离解耦成若干 岩片并相继折返已成为超高压变质岩折返机制研究 的核心争议问题, 它涉及到我们对大陆地壳俯冲行 为与洋壳俯冲行为的差异性认识. 本文以大别-苏鲁 造山带为例, 总结了大陆碰撞过程中与俯冲陆壳拆 离和差异折返模型相关的同位素年代学、岩石地球化 学和变质岩石学等方面的证据, 并讨论了它的科学 意义和有待于进一步解决的有关科学问题, 以期有 助于陆壳俯冲动力学的进一步研究.

\section{1 俯冲陆壳的浅部拆离与差异折返}

1.1 陆壳俯冲开始阶段其上部地壳(低级变质岩)与 下部基底岩石的解耦

已有研究表明北淮阳带东段庐镇关杂岩中的花 岗片麻岩和辉长岩(如山七、城冲岩体)以及苏鲁地区 
的五莲花岗片麻岩等的原岩形成时代为新元古代并 且属于华南陆块北缘的一部分 ${ }^{[17,29,32 ~ 39]}$. 它们以低绿 片岩相-绿帘角闪岩相变质作用为主. 庐镇关杂岩中 花岗片麻岩的角闪石 $\mathrm{Ar}-\mathrm{Ar}$ 年龄 ${ }^{[17]}$ 与锆石 $\mathrm{U}-\mathrm{Pb}$ 年龄 [36,38]一致( 750 Ma), 仍能记录其原岩年龄而未被后 期变质作用干扰; 但其中白云母的 $\mathrm{Ar}-\mathrm{Ar}$ 年龄为 $(241.9 \pm 2.3) \mathrm{Ma}^{[17]}$, 记录了与三叠纪大陆碰撞相关的 变质时代. 这表明这些杂岩在新元古代以后的变质 反应温度都低于角闪石的 $\mathrm{Ar}-\mathrm{Ar}$ 封闭温度 $\left(\sim 500^{\circ} \mathrm{C}\right)$ 而 高于白云母的 $\mathrm{Ar}-\mathrm{Ar}$ 封闭温度 $\left(\sim 350^{\circ} \mathrm{C}\right)$. 因此, 可以 认为它们是陆壳俯冲最初阶段, 最早被拆离、刮下来 的“加积楔”[29,32,39].

类似证据也发现于大别山西部, 刘贻灿等人 ${ }^{[31]}$ 对北淮阳带西段王母观浅变质辉长岩的锆石SHRIMP $\mathrm{U}-\mathrm{Pb}$ 定年的研究结果表明, 其形成时代为新元古代 晚期((635 \pm 5$) \mathrm{Ma})$. 很显然, 北淮阳带西段浅变质辉 长岩的形成年龄与华南陡山沱组沉积岩中普遍发育 的火山凝灰岩夹层的时代(635 Ma左右) ${ }^{[40 \sim 42]}$ 以及华 南陆块北缘(造山带南麓)湖北随州-春阳一带发育的 一期大规模基性岩墙群的时代(630 640 Ma) ${ }^{1}$ 完全一 致. 考虑到新元古代华南陆块北缘存在大规模的岩

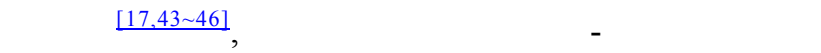
变质(橄榄)辉长岩属于华南陆块北缘的一部分, 它被 后来的构造推覆到华北南缘并就位于华北陆块南缘 的古生代岩浆弧杂岩中 ${ }^{[31]}$. 此外，Liu等人 ${ }^{[19]}$ 曾报道 苏家河附近一个变辉长岩的年龄为 $(582 \pm 11) \mathrm{Ma}$; 陈 玲等人 ${ }^{[47]}$ 也在北淮阳带西段获得柳林变辉长岩的锆 石U-Pb年龄为 $(611 \pm 13) \mathrm{Ma}$. 尽管这些浅变质(橄榄) 辉长岩是否属于同一期形成以及它们之间的相互关系 等尚待进一步查明，但是，这些最新资料给了我们一 个重要启示: 商-麻断裂以西的北淮阳带西段也存在 从华南俯冲陆壳拆离下来的新元古代浅变质岩片. 该 区浅变质岩石为绿穷角闪岩相-绿片岩相 ${ }^{[19,31,48,49]}$, 并 同样记录有 $218 \sim 258 \mathrm{Ma}$ 的云母 K-Ar ${ }^{\left[{ }^{50]}\right.}$ 或 Ar$\mathrm{Ar}^{[17,19,51]}$ 年龄. 因而它们可能是印支期华南陆块发生 深俯冲的初始阶段被解耦的岩片, 并在后期构造作 用过程中被推覆到华北南缘古生代浅变质岩系之上. 因此, 北淮阳带西段这些新元古代浅变质辉长岩的 成因机制可能类似于周建波等人 ${ }^{[32,34,39]}$ 和Zheng等人 ${ }^{[29]}$ 在研究大别-苏鲁造山带北缘浅变质岩时提出
的大陆俯冲过程中被动大陆边缘变形加积楔模型.

1.2 陆壳俯冲初期的壳内解耦和低-中级变质岩片的 折返

近年来, 大别山东段(商城-麻城或商-麻断裂以 东)及苏鲁造山带中陆续发现一些低-中级变质的新 元古代岩石并具有三叠纪变质作用年龄记录, 如大 别山超高压带中的港河绿片岩相岩石(板岩、千枚岩) 有 $(232.2 \pm 8.3) \mathrm{Ma} \mathrm{Rb}-\mathrm{Sr}$ 年龄(全岩等时线)记录和原 岩时代为 760 800 $\mathrm{Ma}^{[52]}$ 以及苏鲁地区超高压带西北 侧(胶北)的粉子山群中大理岩的原岩时代为(786 \pm 67$)$ $\mathrm{Ma}$ 和变质时代为 $(240 \pm 44) \mathrm{Ma}$ (均为锆石 $\mathrm{U}-\mathrm{Pb}$ 年 龄 $)^{[30]}$. 由于白云母的 $\mathrm{Rb}-\mathrm{Sr}$ 体系封闭温度为 $500^{\circ} \mathrm{C}$ 左 右 ${ }^{[53]}$, 而变质锆石的重结晶作用至少需要 $600 \sim 650^{\circ} \mathrm{C}$ 以上的温度 ${ }^{[54]}$, 因此, 大别-苏鲁造山带中这些浅变 质的新元古代岩片属于华南陆块北缘的一部分并被 认为参与了华南陆块的印支期俯冲, 但未经历超高 压变质作用. 这表明这些浅变质岩系有可能是陆壳 深俯冲初期在高绿片岩-角闪岩相阶段解耦的岩片 ${ }^{[30]}$. Tang等人 ${ }^{[30]}$ 提出大陆地壳俯冲过程中出现浅部地壳 拆离, 认为苏鲁造山带北缘粉子山群中大理岩岩片 是随着大陆深俯冲的继续进行和南、北陆块的汇聚被 推覆于华北陆块南缘变质的岩石单位之上的产物.

上述两种浅变质岩片的区别是前者是在陆壳俯 冲初始阶段被解耦的、变质程度低, 因而没发生变质 锆石增生; 后者被拆离解耦时, 陆壳已俯冲到开始大 规模脱水阶段, 变质程度较高(角闪岩相)并有变质锆 石增生发生, 从而记录有三叠纪变质年龄. 这证明俯 冲陆壳在发生榴辉岩相变质前有可能在浅部不同深 度发生了地壳的拆离 [29 31].

\section{2 俯冲陆壳的深部拆离与多板片差异折返}

俯冲陆壳的深部拆离与多板片差异折返, 是指 陆壳俯冲到较大深度(如高压或超高压榴辉岩相变质 深度)发生的地壳拆离与超高压岩石的多板片差异折 返. 这方面证据分别来自大别-苏鲁造山带地表超高 压变质岩研究和苏鲁科学钻探的地下岩芯超高压变 质岩样品的研究.

\section{1 大别山地表出露的超高压变质带证据}

(i ) 大别山超高压变质带由 3 个超高压岩片组 成. 大别-苏鲁造山带位于中国中部华南与华北 2 个 $100 \sim 101$

1) 洪吉安, 马斌. 扬子北缘 Marinoan 期檄长岩岩墙群及其意义. 杭州: 2005 年全国岩石学与地球动力学研讨会论文摘要, 2005. 
大陆板块之间，是世界上最大的含柯石英 ${ }^{[3 \sim 5]}$ 和金刚 石 ${ }^{[7]}$ 的超高压变质岩出露区. 大别山超高压变质带保 留有极好的岩石单位分带. 从南到北, 大别造山带大 致可划分为宿松变质杂岩带、南大别低温榴辉岩带、 中大别中温超高压变质带、北大别高温超高压杂岩带 及等构造岩石单位 ${ }^{[13,17,19,28,29,49,55 ~ 59]}$ (图 1, 表 1). 它们 之间依次分别被太湖-山龙、花凉亭-弥陀、水吼-五河 及磨子潭-晓天等大型断裂带或韧性剪切带所分割. 除了宿松变质杂岩带和北淮阳带没有发现超高压变 质岩, 其余 3 个带都发现了超高压变质岩.

中大别带最早因发现含柯石英和金刚石的超高
压岩石 ${ }^{[4,5,7]}$ 并被证明是三叠纪华南陆块俯冲于华北 陆块之下 $\geq 120 \mathrm{~km}$ 深度发生超高压变质形成的 ${ }^{[60,61]}$. 近期研究表明, 南大别低温榴辉岩中发现有柯石英 假象等超高压变质证据 ${ }^{[58]}$ 以及北大别杂岩带中发现 榴辉岩 ${ }^{[62,63]}$ 并发现有金刚石以及其他超高压变质证 据 ${ }^{[28,62,64 ~ 67]}$; 同时, 北大别杂岩带 ${ }^{228,55,59,68 ~ 71]}$ 和南大 别低温榴辉岩带 ${ }^{[58]}$ 均被证明经过三叠纪超高压变质 作用，因而属于华南俯冲陆壳的一部分. 因此，大别 山印支期深俯冲陆壳包括 3 个超高压岩片即南大别 低温榴辉岩带、中大别超高压变质带和北大别杂岩带 ${ }^{[25]}$ (后文将分别简称南大别、中大别和北大别).

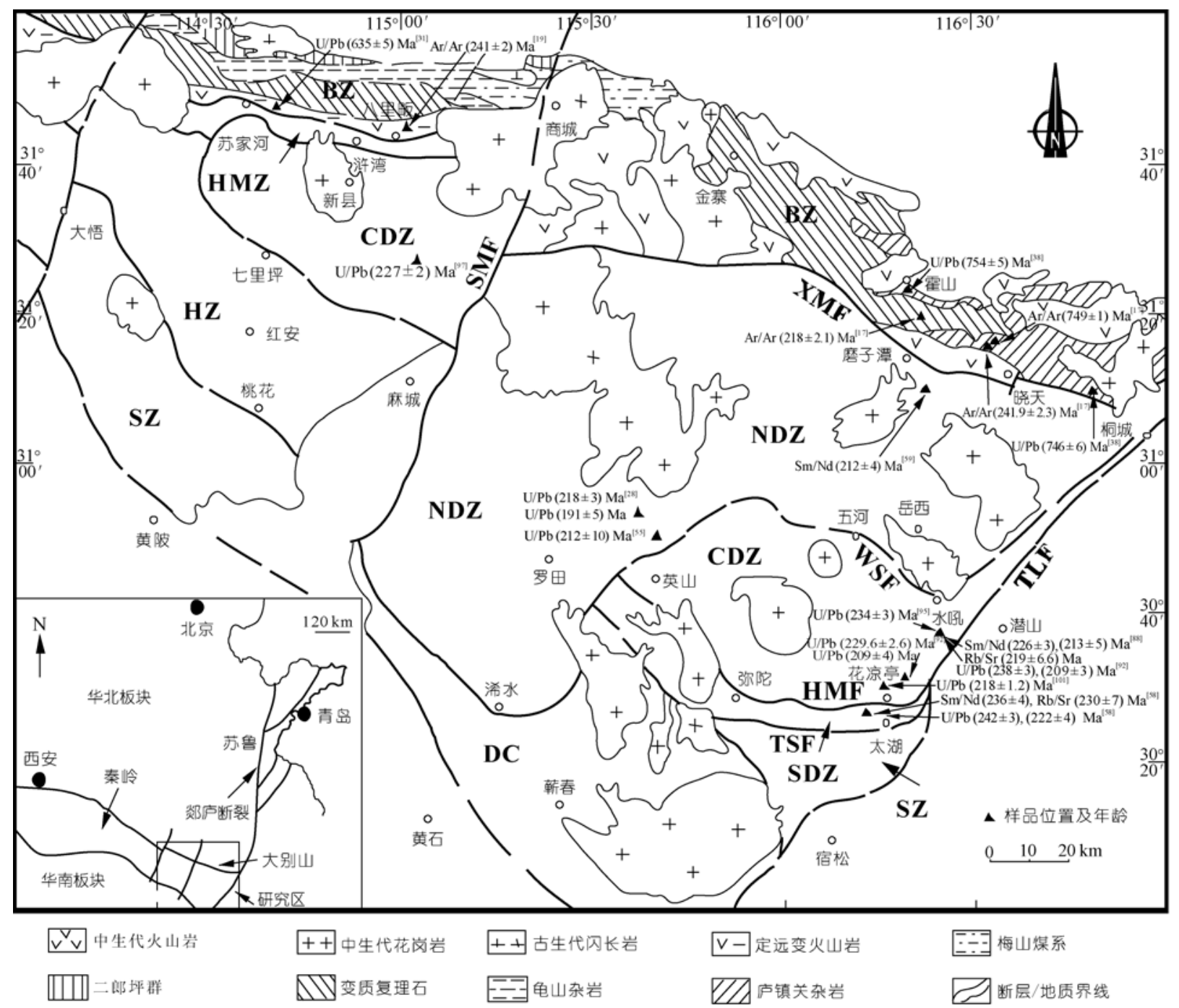

图 1 大别山造山带的地质简图(据文献[55]修改)

BZ，北淮阳带; NDZ，北大别高温超高压杂岩带; CDZ，中大别中温超高压变质带; SDZ，南大别低温榴辉岩带; SZ, 宿松变质杂岩带; HMZ, 浒湾混杂岩带; HZ, 红安低温榴辉岩带; DC, 角闪岩相大别杂岩; XMF, 晓天-磨子潭断裂; WSF, 五河-水吼断裂; HMF, 花 凉亭-弥陀断裂; TSF，太湖-山龙断裂; TLF, 郯庐断裂; SMF，商城-麻城断裂 
(ii) 3 个超高压岩片的差异.

(1) 岩石学差异

北大别主要是一个正片麻岩单位，含有少量榴 辉岩、(含石榴子石)斜长角闪岩和麻粒岩等, 并且, 最近研究已证明至少部分榴辉岩是由基性麻粒岩转 变形成的 ${ }^{[55]}$; 中大别是一个正片麻岩+表壳岩单位, 含有大量榴辉岩透镜体或岩块以及副片麻岩、大理岩 和硬玉石英岩等; 南大别则主要为榴辉岩及(含石榴 子石)二云绿穷斜长片麻岩等一套副变质岩. 3 个超高 压岩片具有不同的含水矿物组合特点(表 1). 如, 北 大别榴辉岩中无多硅白云母或其他高压-超高压含水 矿物, 反映它们变质过程中缺乏流体 ${ }^{[28,55,59]}$; 而中大 别榴辉岩中多硅白云母-䵢穷石等含水矿物普遍存在, 以及南大别榴辉岩中常见到低温高压变质矿物, 硬 柱石-冻蓝闪石, 和钠云母-多硅白云母等含水矿物
[49,58,72 74]，表明中大别和南大别在超高压变质作用期 间富含流体以及它们在变质温度及含水矿物种类方 面存在一定的差异性. 另外, 北大别、中大别超高压 岩石中流体包裹体成分也不同, 如后者主要是具有 不同盐度的水流体，而前者主要是 $\mathrm{N}_{2}$ 和 $\mathrm{CO}_{2}$ ，证明超 高压变质作用期间中大别比北大别富水流体 ${ }^{[75,76]}$.

此外, 北大别超高压变质岩以经历过独特的麻 粒岩相退变质作用而区别于中大别和南大别带, 显 示它们具有不同的折返历史 $[28,55,59,63,67,77,78]$. 而且, 3 个超高压岩片的峰期变质温度由南向北逐渐升高, 即由南大别低温榴辉岩 $\left(T<700^{\circ} \mathrm{C}\right.$ ，一般为 $570 \sim$ $670^{\circ} \mathrm{C}^{[58,79 \sim 81]} \rightarrow$ 中大别中温榴辉岩 $(T$ 一般为 $700 \sim 800$

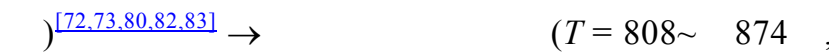
$P=2.5 \mathrm{GPa}$ 或 $\left.904 \sim 963^{\circ} \mathrm{C}, P=4.0 \mathrm{GPa}\right)^{[55,59]}$, 这种峰 期变质温度的有规律变化, 可能分别与 3 个

表 1 大别山不同岩石单位的主要特征

\begin{tabular}{|c|c|c|c|c|c|}
\hline 岩石单位 & 主要组成 & 变质特征 & $\mathrm{Pb}$ 同位素 & 年龄 & 文献 \\
\hline \multirow{6}{*}{$\begin{array}{l}\text { 北淮阳 } \\
\text { 带 }\end{array}$} & 变质复理石 & 绿片岩相 & \multirow{6}{*}{ 高放射成因 $\mathrm{Pb}$} & 白云母 $\mathrm{Ar} / \mathrm{A}(\mathrm{r} 218 \pm 2.1) \mathrm{Ma}$ & [17] \\
\hline & & & & $\mathrm{U} / \mathrm{Pb}(754 \pm 5),(746 \pm 6) \mathrm{Ma}$ & [38] \\
\hline & 庐镇关杂岩 & 绿片岩-绿穷角闪岩相 & & 角闪石 $\operatorname{Ar} / \operatorname{Ar}(749 \pm 1) \mathrm{Ma}$ & [17] \\
\hline & & & & 白云母 $\operatorname{Ar} / \operatorname{Ar}(241.9 \pm 2.3) \mathrm{Ma}$ & [17] \\
\hline & 变辉长岩 & 绿片岩-绿穷角闪岩相 & & $\mathrm{U} / \mathrm{Pb}(635 \pm 5) \mathrm{Ma}$ & [31] \\
\hline & 定远变火山岩 & 绿片岩-绿穷角闪岩相 & & 多硅白云母 $\operatorname{Ar} / \operatorname{Ar}(241 \pm 2) \mathrm{Ma}$ & [19] \\
\hline \multirow{3}{*}{$\begin{array}{l}\text { 北大别 } \\
\text { 带 }\end{array}$} & & 超高压榴辉岩相 $\rightarrow$ 石英榴辉岩相 $\rightarrow$ 麻粒 & \multirow[b]{2}{*}{ 低放射成因 $\mathrm{Pb}$} & $\mathrm{Sm} / \mathrm{Nd}(212 \pm 3) \mathrm{Ma}$ & [59] \\
\hline & 榴辉岩 & $\begin{array}{l}\text { 岩相 } \rightarrow \text { 角闪岩相退变, 峰期缺乏多硅白 } \\
\text { 云母等含水矿物以及高的变质温度, 含 } \\
\text { 金刚石及石榴子石和单斜辉石中普遍 } \\
\text { 发育针状出溶体, 流体包裹体成分主要 } \\
\text { 是 } \mathrm{N}_{2} \text { 和 } \mathrm{CO}_{2}\end{array}$ & & $\mathrm{U} / \mathrm{Pb}(212 \pm 10) \mathrm{Ma}$ & [55] \\
\hline & 花岗片麻岩 & & & $\mathrm{U} / \mathrm{Pb}(218 \pm 3),(191 \pm 5) \mathrm{Ma}(\mathrm{r})$ & [28] \\
\hline \multirow{8}{*}{$\begin{array}{l}\text { 中大别 } \\
\text { 带 }\end{array}$} & \multirow{5}{*}{ 榴辉岩 } & \multirow{5}{*}{$\begin{array}{l}\text { 超高压榴辉岩相 } \rightarrow \text { 石英榴辉岩相 } \rightarrow \text { 角闪 } \\
\text { 岩相, 峰期含䵢穷石、多硅白云母等含 } \\
\text { 水矿物, 流体包裹体成分主要为不同盐 } \\
\text { 度的水流体 }\end{array}$} & \multirow{5}{*}{ 高放射成因 $\mathrm{Pb}$} & $\mathrm{Sm} / \mathrm{Nd}(226 \pm 3) \mathrm{Ma}$ & [88] \\
\hline & & & & $\mathrm{Rb} / \mathrm{Sr}(219 \pm 6.6) \mathrm{Ma}$ & [88] \\
\hline & & & & $\mathrm{U} / \mathrm{Pb}(234 \pm 3) \mathrm{Ma}$ & [95] \\
\hline & & & & $\mathrm{U} / \mathrm{Pb}(229.6 \pm 2.6),(209 \pm 4) \mathrm{Ma}$ & [92] \\
\hline & & & & $\mathrm{U} / \mathrm{Pb}(218 \pm 1.2) \mathrm{Ma}$ & [101] \\
\hline & 石英硬玉岩 & & & $\mathrm{U} / \mathrm{Pb}(227 \pm 2) \mathrm{Ma}$ & [97] \\
\hline & 片麻岩 & & & $\mathrm{U} / \mathrm{Pb}(238 \pm 3),(209 \pm 3) \mathrm{Ma}$ & [92] \\
\hline & 大理岩 & & & $\mathrm{Sm} / \mathrm{Nd}(213 \pm 5) \mathrm{Ma}$ & [88] \\
\hline \multirow{4}{*}{$\begin{array}{l}\text { 南大别 } \\
\text { 带 }\end{array}$} & \multirow{3}{*}{ 榴辉岩 } & 超高压榴辉岩相 $\rightarrow$ 石英榴辉岩相 $\rightarrow$ 角闪 & & $\mathrm{Sm} / \mathrm{Nd}(236 \pm 4) \mathrm{Ma}$ & [58] \\
\hline & & 岩相, 峰期富䵢穷石、多硅白云母、硬 & & $\mathrm{Rb} / \mathrm{Sr}(230 \pm 7) \mathrm{Ma}$ & [58] \\
\hline & & 柱石等含水矿物以及较低的变质温度 & & $\mathrm{U} / \mathrm{Pb}(242 \pm 3) \mathrm{Ma},(222 \pm 4) \mathrm{Ma}(\mathrm{r})$ & [58] \\
\hline & $\begin{array}{l}\text { 片麻岩 } \\
\text { 大理岩 }\end{array}$ & & & & \\
\hline
\end{tabular}

a) $\mathrm{U} / \mathrm{Pb}$ 年龄为变质锆石或独居石的 SHRIMP 定年或金红石的定年结果, $\mathrm{r}$ 表示锆石或独居石的增生边; $\mathrm{Sm} / \mathrm{Nd}$ 年龄为榴辉岩相或 角闪岩相变质矿物 3 个以上分析点确定的等时线结果 
UHP岩片的原岩在俯冲陆壳内所处的位置有关, 即 南大别和北大别分别相当于上、下地壳, 也就是说, 3 个岩片原岩温度就有高、低区别 28,55$]$. 这也与前文 所述的 3 个岩片的岩石组成及其含水矿物和流体成 分的特点相吻合.

因此, 鉴于南大别和中大别含有较多的表壳岩、 富含水矿物和流体包体以及较低的峰期变质温度并 结合它们各自的岩石组合特点, 推测它们分别来自 俯冲上地壳的上、下部; 而北大别则因峰期缺乏含水 矿物、富 $\mathrm{N}_{2}$ 和 $\mathrm{CO}_{2}$ 包体、较高的峰期变质温度以及榴 辉岩由镁铁质麻粒岩转变形成等而推测来自于俯冲 下地壳. 同时考虑它们有不同的变质 $P-T$ 演化历史, 由 此说明印支期华南陆壳俯冲过程中有可能在不同深 度发生了壳内的解耦 $[27 \sim 31,84]$.

(2) 地球化学和年代学差异

由于上、下地壳的 $\mathrm{U} / \mathrm{Pb}$ 及 $\mathrm{Pb}$ 同位素组成有明显差 异，因此 $\mathrm{Pb}$ 同位素可以用来示踪地壳性质，即下部地 壳相对亏损 $\mathrm{U}$ 和 $\mathrm{Th}$ 以及贫放射性成因 $\mathrm{Pb}$ 同位素组成, 而上部地壳相对富集放射性成因 $\mathrm{Pb}$ 同位素组成 ${ }^{[85,86]}$. 已有的 $\mathrm{Pb}$ 同位素研究表明北大别与中大别岩片的 $\mathrm{Pb}$ 同位素组成不同, 中大别超高压变质岩比北大别变 质岩有更高的放射成因 $\mathrm{Pb}$, 具上地壳特征, 而北大别 的低 ${ }^{206} \mathrm{~Pb} /{ }^{204} \mathrm{~Pb}$ 值反映了下地壳特征 ${ }^{[23,87]}$, 因而代表 了上、下不同层位的俯冲陆壳. 进一步证明大别山不 同的超高压岩片分别来自于不同性质的俯冲陆壳.

北大别片麻岩的锆石SHRIMP U-Pb年龄结果表 明, 超高压变质时代为 $(218 \pm 3) \mathrm{Ma}^{[28]}$, 而北大别榴 辉岩的 2 石榴子石 +2 绿辉石的 $\mathrm{Sm}-\mathrm{Nd}$ 等时线年龄为

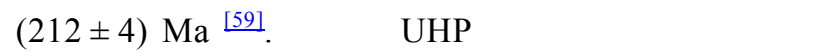
被很好测定, 且老于北大别. 如, 由 3 个榴辉岩相矿 物确定的Sm-Nd等时线年龄为 $(226 \pm 3) \mathrm{Ma}^{[88]}$; 锆石 $\mathrm{U}-\mathrm{Pb}$ 测定的精确年龄为 $225 \sim 238 \mathrm{Ma}^{[43,44,89 \sim 97]}$. 南大 别低温榴辉岩的峰期变质时代最老, 如石榴子石+绿 辉石 + 金红石+蓝晶石的 Sm-Nd矿物等时线年龄为 $(236 \pm 4) \mathrm{Ma}$ 和锆石 $U-\mathrm{Pb}$ 年龄为 $(242 \pm 3) \sim(243 \pm 4)$ $\mathrm{Ma}^{[58,98]}$. 此外, 苏鲁超高压带中对应于中大别超高 压带的超高压片麻岩锆石SHRIMP U-Pb年龄研究也 表明，含柯石英等超高压矿物的锆石幔部年龄为 231 227 Ma等 ${ }^{[99,100]}$, 而含石英等角闪岩相退变质矿 物的锆石边部年龄为 $(211 \pm 4) \mathrm{Ma}$. 该超高压片麻岩 锆石的幔、边部年龄正好分别与中大别超高压带及北 大别带的峰期变质时代一致. 这些表明, 3 个超高压
岩片的峰期变质时代, 由南向北逐渐变新, 并且, 中 大别超高压带岩石的退变质年龄, 如双河片麻岩退 变质矿物 $\mathrm{Sm}-\mathrm{Nd}$ 年龄为 $(213 \pm 5) \mathrm{Ma}^{[88]}$; 双河石英硬 玉岩和毛屋榴辉岩中独居石的退变边年龄为 $(209 \pm 3)$

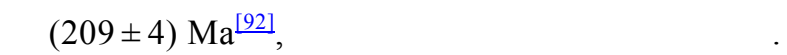

综合已发表的年代学和岩石学资料, 可以绘出 大别山 3 个超高压岩片的冷却 $T$ - $t$ 曲线(图 2). 图 2 反 映它们明显具有不同的抬升冷却历史和演化过程, 这与前文分析一致. 此外, 从图 2 还可以看出, 北大 别具有相对慢的冷却速率, 而中大别与南大别却有 快速的冷却过程. 这也许是北大别榴辉岩很少见有 保留早期超高压变质证据的重要原因, 因为慢的抬 升速率及高温 $\left(\geq 800^{\circ} \mathrm{C}\right)$ 条件下有可能使超高压岩石 部分或全部转变为低压矿物组合, 如早期柯石英可 能转变为石英(目前呈包体形式存在于石榴子石中和 主晶石榴子石伴有放射状裂纹 $)^{[55,78]}$.

\section{2 苏鲁地表出露的超高压变质带证据}

苏鲁超高压变质带也可类似大别山划分出若干 岩片. Xu等人 ${ }^{[27]}$ 将苏鲁超高压变质带划分成 4 带: 南 苏鲁高压变质带 (I)、中苏鲁很高压变质带 $($ II )、北 苏鲁超高压变质表壳岩带 (III) 和北苏鲁超高压花岗 质变质岩带(IV)(图 3). 根据文献[27], 现将其主要特 征简单介绍如下.

带 | 经历了 $0.7 \sim 0.85 \mathrm{GPa}, 300 \sim 360^{\circ} \mathrm{C}$ 的蓝片岩 相变质及绿片岩相退变质作用; 带 III 经历了 $1.5 \sim 2.5$ $\mathrm{GPa}, 500 \sim 600^{\circ} \mathrm{C}$ 的很高压变质作用及蓝片岩相退变 质作用; 带 III 主要由含柯石英超高压变质表壳岩及 榴辉岩和超镁铁质岩透镜体组成, 峰期变质温度和 压力为 $2.8 \sim 3.0 \mathrm{GPa}, 750 \sim 850^{\circ} \mathrm{C}$; 带IV 的主要组分为 花岗质片麻岩、少量变质表壳岩夹榴辉岩和超镁铁质 岩块体，不同类型岩石都含有柯石英，证明该带经历 了超高压变质作用. 它们分别大致相当于大别山的 宿松变质杂岩带、南大别低温榴辉岩带、中大别超高 压带和北大别杂岩带. 而且, 南苏鲁高压变质带的峰 期变质时代为 $253 \mathrm{Ma}$ 、折返时代为 240 253 Ma和北 苏鲁超高压变质带的峰期变质时代为 $240 \sim 220 \mathrm{Ma}$, 折返时代为 $200 \sim 220 \mathrm{Ma}^{[27,61,95,99,100,102 ~ 104]}$, 表明从南 到北, 峰期变质时代和折返时代逐渐变年轻, 类似于 大别山. 因而, 在苏鲁造山带同样存在俯冲陆壳内部 的多层次拆离解耦与多板片折返过程. 


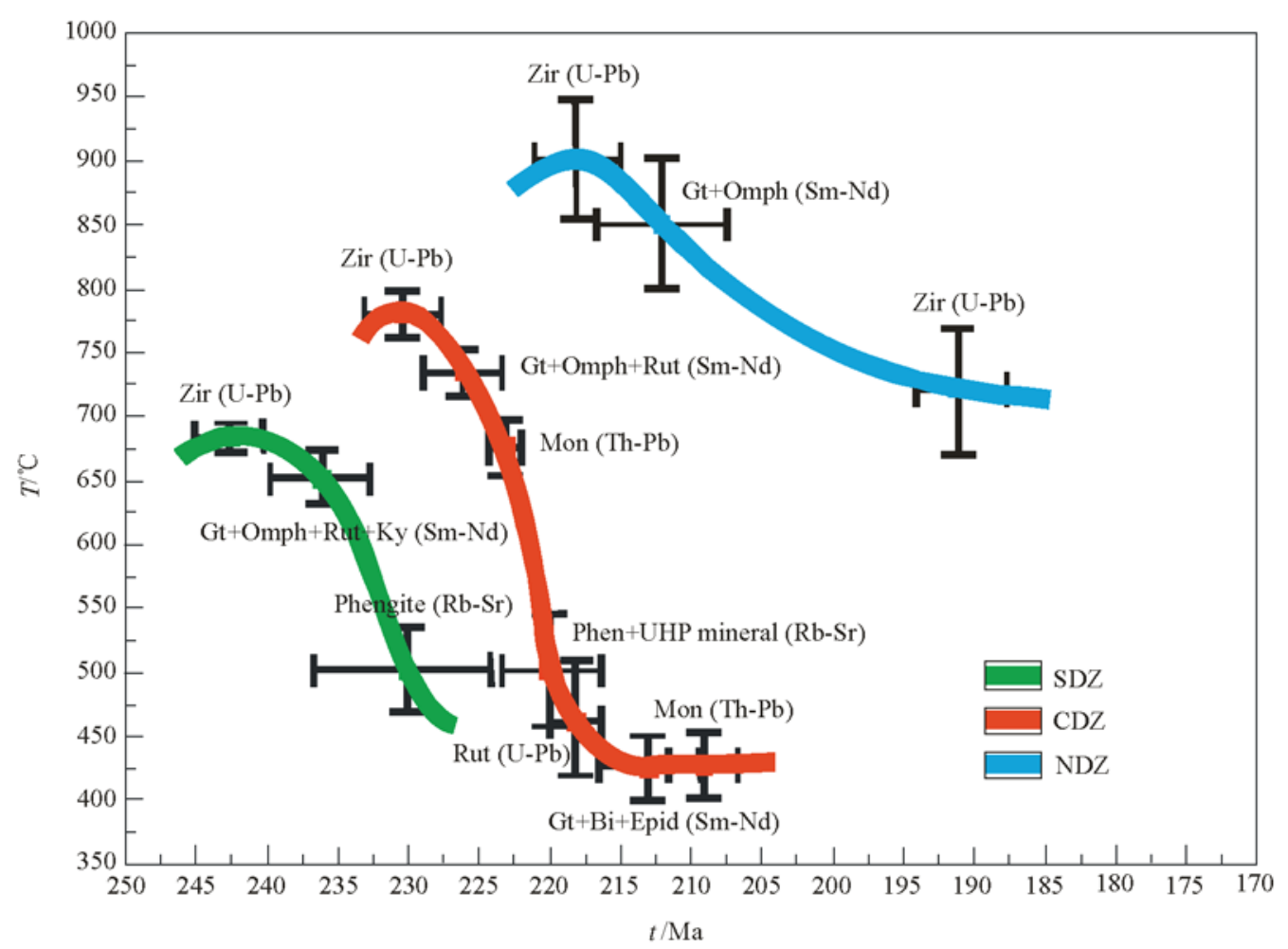

图 2 大别山 3 个超高压岩片的冷却 $T-t$ 曲线

SDZ-南大别低温榴辉岩带, CDZ-中大别中温超高压变质带, NDZ-北大别高温超高压杂岩带. 资料来源: 文献[28, 55, 58, 59, 88, 92 95, 101]

\section{3 苏北大陆科学深钻岩芯揭示的超高压带垂向多} 岩片叠置证据

Dong等人 ${ }^{[105]}$ 通过反射地震剖面揭示了中大别 超高压变质带在垂向上也是由若干岩片叠置而成的. 在苏北东海(位于图 3 第 III 超高压变质带)实施的大陆 科学钻探为直接观察者以深部岩片叠置状况提供了 条件. 董锋等人 ${ }^{[106]}$ 通过对苏北大陆科学钻探(CCSD) 100 2000 m岩芯的普通 $\mathrm{Pb}$ 同位素研究揭示了苏鲁超 高压带 III地表至 $2000 \mathrm{~m}$ 深度在垂向上超高压岩片的 叠置状况(图 4).

图 $4 \mathrm{~Pb}$ 同位素显示该岩芯可划为 3 个岩段: 即 100 800，800 1600 和 1600 2000 m上、中、下 3 个 岩段. 上岩段具有高放射成因 $\mathrm{Pb}$ 特征, 下岩段具有低 放射成因 $\mathrm{Pb}$ 特征, 两者有显著差别, 它们分别是从俯 冲大陆岩石圈解耦的上地壳和中地壳岩片. 中部岩 段发育有韧性剪切带, 其 $\mathrm{Pb}$ 同位素特征介于上下岩 段之间, 可能是上、下岩段 $\mathrm{Pb}$ 同位素的混合结果, 因 此被解释为上、下岩片之间的拆离带. 考虑到中部岩 段又具有异常低 $\delta^{18} \mathrm{O}$ 峰值 ${ }^{[107,108]}$, 该拆离面可能是在 地壳内部晚元古代的断裂带及冷水活动通道基础上
发育起来的, 该水-岩交换作用导致中部岩段原岩的 低 $\delta^{18} \mathrm{O}$ 峰值和弱的力学强度. 据此, 董锋等人 ${ }^{[106]}$ 提 出在大陆岩石圈俯冲过程中, 上部岩片同俯冲的大 陆岩石圈发生拆离, 率先沿着这一个拆离面逆冲折 返至浅部.下岩片是随后从俯冲岩石圈解耦的中地 壳岩片, 并折返至浅部, 并下伏在先期折返的上部岩 片之下.

2.4 大别山俯冲陆壳内部的多层次解耦与超高压岩 石的多板片差异折返模型

上述大别山构造岩石单位的分布以及不同超高 压岩片的岩石学、年代学和地球化学特征, 可以用印 支期华南大陆深俯冲过程中俯冲陆壳内部的多层次 拆离解耦以及多板片差异折返模型 ${ }^{[24,25,28]}$ 来解释: 即 陆壳俯冲过程中, 首先在俯冲上地壳中发生拆离解 耦, 上部岩片(如南大别低温榴辉岩带)沿拆离面逆冲 折返, 下部陆壳继续俯冲; 此后, 在上、下地壳之间 发生第二次解耦, 上部岩片(中大别UHP带) 沿拆离 面逆冲折返, 下地壳(北大别杂岩带)继续俯冲; 最终, 在俯冲板片断离后, 长英质下地壳与下伏镁铁质下 地壳和岩石圈地幔拆分解耦, 3 个岩片全部折返, 并 


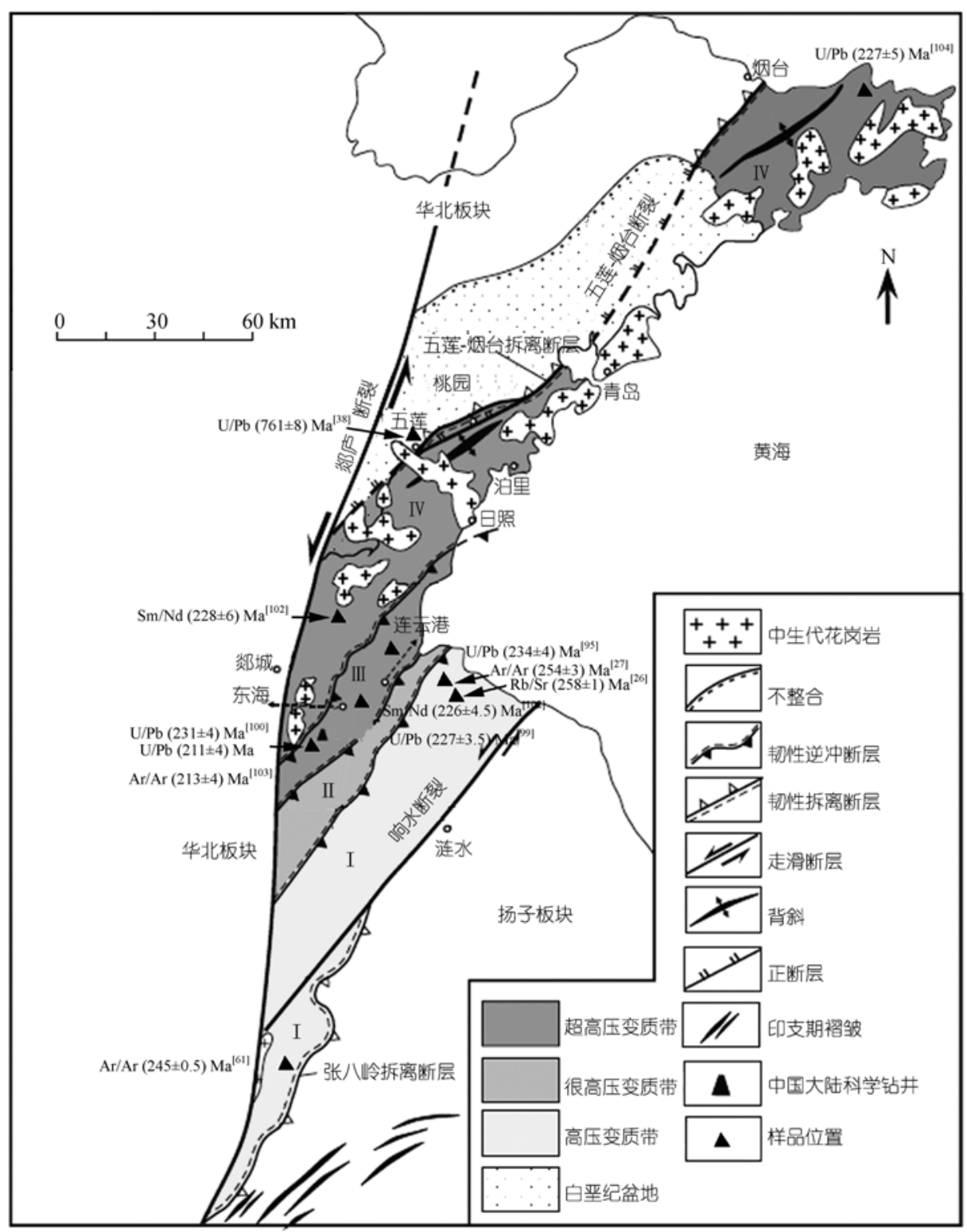

图 3 苏鲁超高压变质带构造简图(据文献[27]修改)

I -高压变质带; II -很高压变质带; II 和IV-超高压变质带

呈现出大别山(或苏鲁带)由南向北 3 个岩片峰期变质 时代逐步变新、变质温度逐步升高的趋势.

\section{3 俯冲陆壳内部拆离的岩石流变学证据}

在陆壳俯冲过程中陆壳内部发生拆离和脱耦是 由于陆壳内部存在力学强度薄弱带的结果. 陆壳整 体与岩石圈地幔脱耦并折返模型的基本假设是基于 大陆岩石圈强度的果酱三明治(jelly sandwich)模型, 即刚性的上地壳和地幔岩石圈夹着低黏度软弱的下 地壳 ${ }^{[22]}$. 俯冲陆壳多层次解离及多岩板折返模型的
理论基础是大陆岩石圈强度不再是果酱三明治模型, 根据合理的地热梯度和岩石圈成分所获得的岩石圈 的秥度(viscosity)与深度(depth)关系的模拟结果表明, 在陆壳内部至少存在 2 个低黏度带 ${ }^{[109]}$. 因此, 大陆 在俯冲过程中, 由于大陆地壳上、下不同部位岩石组 成的差异以及它们具有不同的力学性质和地球化学 成分等, 有可能沿不同深度的低秥度带发生壳内拆 离解耦, 形成几个高压-超高压变质的板片并逆冲折 返. 此外, 对苏北大陆科学钻探(CCSD) 岩芯的普通 $\mathrm{Pb}$ 和氧同位素研究还发现俯冲陆壳内的古断层带因 


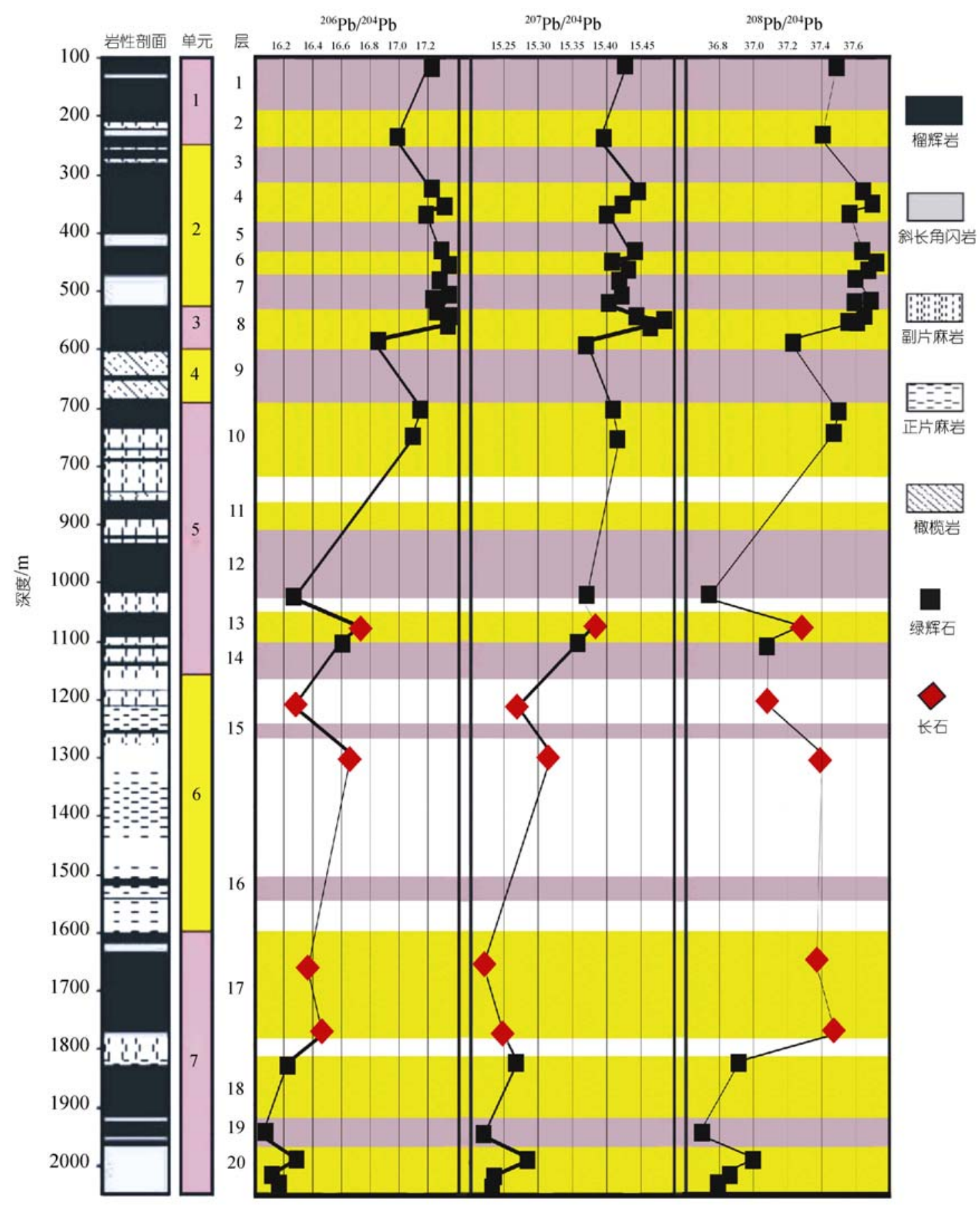

图 4 CCSD 100 2000 m榴辉岩中绿辉石和片麻岩中长石普通Pb同位素比值剖面图

其曾是流体通道及所发生的水岩作用而弱化, 也能 在俯冲过程中发育成壳内拆离面 ${ }^{[106]}$.

\section{4 科学意义及有待于进一步解决的问题}

\section{1 科学意义}

板块构造理论的出现，使人们对大陆的碰撞过
程有了较深入的理解. Oxburgh ${ }^{[110]}$ 最早根据阿尔卑斯 造山带的研究, 发现岩石圈曾沿下地壳与上地幔之 间发生裂开(split)、上覆薄的地壳板片与下伏板片发 生拆离, 进而提出薄板构造 (crustal flake或flake tectonics)概念并用来解释一些复杂的板块边缘特征. 在 此基础之上, 许靖华 ${ }^{[111]}$ 在研究特提斯造山带的形成 
过程时, 发现由于在地壳的内部或底部存在拆离带 (detachment horizons) 以及板块运动而常常导致地壳 的双重或三重叠置, 提出了薄皮板块构造模式 (thin-skinned plate-tectonic model), 并用此模式来解 释阿尔卑斯等碰撞型造山带的形成并认为碰撞型造 山带主要由仰冲壳楔(overriding crustal wedge)、碰撞 混杂岩(collision mélange)和俯冲壳楔(underthrusting crustal wedge)等基本构造单元所组成. 目前, 地壳的 拆离(crustal detachment)已被认为是与板块俯冲相联 系的一种重要地质过程并被理论和地震实验所证实 (如文献[112]及其所引用参考文献).

大陆碰撞过程中的多层次地壳拆离与多板片差 异折返模型的建立，是上述薄皮板块构造模式在大 陆深俯冲过程中的体现和发展. 它突破了传统的陆 壳整体俯冲与整体折返的固定模式，同时，这也是陆 壳俯冲与洋壳俯冲的主要区别. 这种深俯冲陆壳呈 多板片折返的过程是大陆岩石圈组成和力学性质高 度不均一性, 因而存在多个低黏滞带的结果, 是大陆 板块运动有别于大洋板块的实际例证. 而且, 这种俯 冲陆壳内部的地壳拆离作用可能是引起壳内浅源地 震的重要原因之一. 因此, 通过进一步研究, 不仅有 助于大陆动力学研究并发展板块构造理论, 而且对探 讨地壳浅源地震的原因和发生机制等具有重要意义.

\section{2 有待于进一步解决的问题}

尽管俯冲陆壳多层次解离及多岩板差异折返模 型有上述证据的支持，然而仍存在两方面问题. 查明 这些问题尚需开展更深入的岩石学、年代学和地球化 学等方面的研究工作.

（i ）不同岩片提供的证据是不均衡的，部分证 据的可靠性需要更深入工作加以验证. 如北大别带 和南大别带的精确变质年龄偏少, 还难以建立如中 大别带一样精确的 $T$ - $t$ 冷却曲线. 为此, 在今后的研 究中加强对这两个岩片的高压-超高压变质岩进行精 确定年和冷却史研究. 其中, 2 个岩片的峰期变质时 代的确定是关键. 再如, 前人对地表不同岩片的 $\mathrm{Pb}$ 同 位素填图研究仅局限在中大别和北大别带, 南大别
带和苏鲁带都未开展工作; 更为重要的是前人工作 主要是做全岩 $\mathrm{Pb}$, 但由于地表风化等因素的影响而 使全岩 $\mathrm{U} / \mathrm{Pb}$ 可发生较大变化, 给初始 $\mathrm{Pb}$ 同位素组成 的年龄校正计算带来误差. 因此, 有必要在地表出露 的各主要岩片中开展如董锋等人 ${ }^{[106]}$ 在大陆科学钻探 岩芯研究中进行的超高压变质岩普通 $\mathrm{Pb}$ 地球化学填 图.

(ii ) 对于陆壳俯冲过程中陆壳内部的拆离解耦 及多板片差异折返的精细过程我们尚有许多问题不 清楚, 已提出的模型尚有一些不完善之处.

如我们并不清楚部分北淮阳浅变质岩片的变质 时代是代表俯冲时代还是构造就位时代，以及新元 古代晚期浅变质岩石是被何种构造运动从华南推覆 并就位于华北陆块南部活动陆缘的? 这是由于过去 北淮阳带和造山带南麓(如随州-妻阳一带)的浅变质 岩石的研究相对薄弱, 如前文所述, 北淮阳带西段的 新元古代晚期浅变质辉长岩是否经历过三叠纪变质 作用以及它们的就位机制等仍是急需解决的重要科 学问题.

再如, 依据上述俯冲陆壳多层次解离及多岩板 差异折返模型, 大别山南、中、北大别 3 个超高压岩 片的峰期变质年龄差异仅代表了相应岩片拆离、折 返时代的差异, 因此, 这 3 个岩片的俯冲深度应该不 同. 南大别带仅发现柯石英, 尚未发现金刚石, 其俯 冲深度较浅. 但是, 已有证据表明大别山中、北大别 2 个超高压岩片的俯冲深度没有显著差别, 它们均 发现有金刚石 ${ }^{[7,28,65,66]}$. 尽管石榴子石中单斜辉石 + 金 红石+磷灰石等针状矿物出溶体显示, 北大别超高压 岩石的峰期变质压力可能比中大别和南大别高 ${ }^{[66]}$, 但尚需要对北大别带开展更深入的岩石学研究, 寻 找更多的证据加以证实; 否则, 这 3 个岩片的折返过 程并不都像上述模型那样简单, 我们尤其需要对北大 别带开展更深入地峰期变质条件、退变质岩石学和精 细年代学研究, 揭示它真实地折返、抬升轨迹, 进一步 完善大别山超高压变质带的多岩板差异折返模型. 类 似的问题对苏鲁 III, IV 超高压变质带也同样存在. 
Mineral Petrol, 1984, 86: 107-118[doi]

2 Smith D C. Coesite in clinopyroxene in the Caledonides and its implications for geodynamics. Nature, 1984, 310: 641-644[doi]

$3 \mathrm{Xu}$ Z. Etude tectonique et microtectonique de la chaine paleozoique et triasique des Qinlings (Chine). These de doctorat, Univ Sci Tech. Languedoc, Montpeuier, 1987

4 Okay A I, Xu S, Sengör A M C. Coesite from the Dabie Shan eclogites, central China. Eur J Mineral, 1989, 1: 595-598

5 Wang X, Liou J G, Mao H K. Coesite-bearing eclogites from the Dabie Mountains in central China. Geology, 1989, 17: 1085$1088 \underline{\text { [doi] }}$

6 Sobolev N V, Shatsky V S. Diamond inclusions in garnets from metamorphic rocks: A new environment for diamond formation. Nature, 1990, 343: 742-746[doi]

7 Xu S, Okay A I, Ji S, et al. Diamonds from the Dabie Shan metamorphic rocks and its implication for tectonic setting. Science, 1992, 256: $80-82$ [doi]

8 Okay A I, Sengör A M C. Evidence for intracontinental thrust-related exhumation of the ultrahigh-pressure rocks in China. Geology, 1992, 20: 411-414[doi]

9 Chemenda A I, Mattauer M, Bokun A N. Continental subduction and a mechanism for exhumation of high-pressure metamorphic rocks: New modelling, field data from Oman. Earth Planet Sci Lett, 1996, 143: 173-182 [doi]

10 Maruyama S, Liou J G, Zhang R. Tectonic evolution of the ultrahigh-pressure (UHP) and high-pressure (HP) metamorphic belts from central China. Island Arc, 3: 112-121

11 Faure M, Lin W, Shu L, et al. Tectonics of the Dabieshan (eastern China) and possible exhumation mechanism of ultra high-pressure rocks. Terra Nova, 1999, 11: 251-258 $\underline{\text { [doi] }}$

12 钟增球, 索书田, 游振东. 大别山高压、超高压变质期后伸展构造格局. 地球科学一中国地质大学学报, 1998, 23(3): $225-229$

13 索书田, 钟增球, 游振东. 大别地块超高压变质期后伸展变形及超高压变质岩石折返过程. 中国科学 D 辑: 地球科学, 2000 , 30(1): $9-17$

14 Ernst W G, Maruyama S, Wallis S. Buoyancy-driven, rapid exhumation of ultrahigh-pressure metamorphosed continental crust. Proc Natl Acad Sci USA, 1997, 94: 9532-9537

15 Dong S, Chen J, Huang D. Differential exhumation of tectonic units and ultrahigh-pressure metamorphic rocks in the Dabie Mountains, China. Island Arc, 1998, 7: 174-183[doi]

16 Wang Q, Cong B. Exhumation of UHP Terranes: A case study from the Dabie Mountains, eastern China. Int Geol Rev, 1999, 41: 994 $-1004$

17 Hacker B R, Ratschbacher L, Webb L, et al. Exhumation of ultrahigh-pressure continental crust in east central China: Late Triassic-Early Jurassic tectonic unroofing. J Geophys Res, 2000, 105 (B6): 13339—13364 [doi]

18 Ratschbacher L, Hacker B R, Webb L E, et al. Exhumation of the ultrahigh-pressure continental crust ineast-central China: Cretaceous and Cenozoic unroofing and the Tan-Lu fault. J Geophys Res, 2000, 105: 13303-13338[doi]

19 Liu X C, Jahn B M, Liu D, et al. SHRIMP U-Pb zircon dating of a metagabbro and eclogites from western Dabieshan (Hong'an Block), China, and its tectonic implications. Tectonophysics, 2004, 394: 171-192[doi]

20 Chemenda A I, Mattauer M, Malavieille J, et al. A mechanism for syn-collisional rock exhumation and associated normal faulting: Results from physical modeling. Earth Planet Sci Lett, 1995, 132: 225-232 [doi]

21 Massonne H J. Involvement of crustal material in delamination of the lithosphere after continent-continent collision. Int Geol Rev, 2005, 47: 792-804 [doi]

22 Zuber M T. Folding a jelly sandwich. Nature, 1994, 371: 650-651 [doi]

23 李曙光, 黄方, 周红英, 等. 大别山双河超高压变质岩及北部片麻岩的 U-Pb 同位素组成一对超高压岩石折返机制的制约. 中国科学 D 辑: 地球科学, 2001, 31(12): 977-984

24 李曙光, 李秋立, 侯振辉, 等. 大别山超高压变质岩的冷却史及折返机制. 岩石学报, 2005, 21: 1117-1124

25 刘贻灿，李曙光．大别山下地壳岩石及其深俯冲. 岩石学报, 2005, 21(4): 1059-1066

26 许志琴, 曾令森, 梁风华, 等. 大陆板片多重性俯冲与折返的动力学模式一苏鲁高压-超高压变质地体的折返年龄限定. 岩 石矿物学杂志, 2005, 24: 357-368

27 Xu Z Q, Zeng L S, Liu F L, et al. Polyphase subduction and exhumation of the Sulu high-pressure-ultrahigh-pressure metamorphic terrane. Geol Soc Am Spec Paper, 2006, 403: 792-113

28 Liu Y C, Li S, Xu S. Zircon SHRIMP U-Pb dating for gneiss in northern Dabie high T/P metamorphic zone, central China: Implication for decoupling within subducted continental crust. Lithos, 2007, 96: 170-185[ [doi] 
29 Zheng Y F, Zhou J B, Wu Y, et al. Low-grade metamorphic rocks in the Dabie-Sulu orogenic belt: A passive-margin accretionary wedge deformed during continent subduction. Int Geol Rev, 2005, 47: 851-871 [doi]

30 Tang J, Zheng Y F, Wu Y B, et al. Zircon SHRIMP U-Pb dating, C and O isotopes for impure marbles from the Jiaobei terrane in the Sulu orogen: Implication for tectonic affinity. Precambrian Res, 2006, 144: 1-18 $\underline{\text { [doi] }}$

31 刘贻灿, 李曙光, 古晓锋, 等. 北淮阳王母观橄榄辉长岩的锆石 SHRIMP U-Pb 年龄及其地质意义. 科学通报, 2006, 51(18): 2175 - 2180

32 周建波, 郑永飞, 李龙, 等. 扬子板块俯冲的构造加积楔. 地质学报, 2001, 75(3): 338-352

33 周建波, 郑永飞, 吴元保. 苏鲁造山带西北缘五莲花岗岩中锆石 U-Pb 年龄及其地质意义. 科学通报, 2002, 47(22): 1745-1750

34 周建波, 刘建辉, 郑常青. 苏鲁造山带浅变质岩的成因及其大地构造意义. 地质学报, 2005, 79(4): 475一-486

35 谢智, 陈江峰, 张巽, 等. 北淮阳新元古代基性侵入岩年代学初步研究. 地球学报, 2002, 23(6): 517-520

36 郑永飞, 吴元保, 赵子福, 等. 大别山北麓发现新元古代低 ${ }^{18} \mathrm{O}$ 岩浆岩. 科学通报, 2004, 49(14): 1468-1470

37 江来利, Wolfgang Siebel, 陈福坤, 等. 大别造山带北部卢镇关杂岩的 U-Pb 锆石年龄. 中国科学 D 辑: 地球科学, 2005, 35(5): $411-419$

38 Wu Y B, Zheng Y F, Tang J, et al. Zircon U-Pb dating of water-rock interaction during Neoproterozoic rift magmatism in South China. Chem Geol, 2007, 246: 65-86[doi]

39 Zhou J B, Wilde S A, Zhao G C, et al. SHRIMP U-Pb zircon dating of the Wulian Complex: Defining the boundary between the North and South China Cratons in the Sulu Orogenic Belt, China. Precambrian Res, 2008, 162: 559-576

40 储雪蕾, Wolfgang T, 张启锐, 等. 南华-震旦系界线的锆石 U-Pb 年龄. 科学通报, 2005, 50(6): 600-602

41 Condon D, Zhu M, Bowring S, et al. U-Pb Ages from the Neoproterozoic Doushantuo Formation, China. Science, 2005, 308: 9598 [doi]

42 Yin C, Tang F, Liu Y, et al. U-Pb zircon age from the base of the Ediacaran Doushantuo Formation in the Yangtze Gorges, South China: Constraint on the age of Marinoan glaciation. Episodes, 2005, 28: 48-49

43 Rowley D B, Xue F, Tucker R D, et al. Ages of ultrahigh pressure metamorphism and protolith orthogneisses from the eastern Dabie Shan: U/Pb zircon geochronology. Earth Planet Sci Lett, 1997, 151: 191-203[doi]

44 Hacker B R, Ratschbacher L, Webb L E, et al. Zircon ages constrain the architecture of the ultrahigh-pressure Qinling-Dabie orogen, China. Earth Planet Sci Lett, 1998, 161: 215-230 [doi]

45 Zheng Y F, Fu B, Gong B, et al. Stable isotope geochemistry of ultrahigh pressure metamorphic rocks from the Dabie-Sulu orogen in China: Implications for geodynamics and fluid regime. Earth Sci Rev, 2003, 62: 105-161 [doi]

46 Zheng Y F, Wu Y, Chen F K, et al. Zircon U-Pb and oxygen isotope evidence for a large-scale ${ }^{18} \mathrm{O}$ depletion event in igneous rocks during the Neoproterozoic. Geochim Cosmochim Acta, 2004, 68: 4145一4165[doi]

47 陈玲, 马昌前, 余振兵, 等. 大别山北淮阳构造带柳林辉长岩: 新元古代晚期裂解事件的记录. 地球科学一中国地质大学 学报, 2006, 31: 578一-584

48 叶伯丹, 简平, 许俊文, 等. 桐柏-大别造山带北坡苏家河地体拼接带及其构成和演化. 武汉: 中国地质大学出版社, 1993. $1-81$

49 徐树桐, 刘贻灿, 江来利, 等. 大别山造山带的构造几何学和运动学. 合肥: 中国科学技术大学出版社, 2002. 1一 133

50 陈江峰, 董树文, 邓衍尧, 等. 大别造山带钾氩年龄解释一差异抬升的地块. 地质论评, 1993, 39(1): 17一 22

51 Ratschbacher L, Franz L, Enkelmann E, et al. The Sino-Korean-Yangtze suture, the Huwan detachment, and the Paleozoic-Tertiary exhumation of (ultra) high-pressure rocks along the Tongbai-Xinxian-Dabie Mountains. In: Hacker B R, McClelland W C, Liou J G, eds. Ultrahigh-pressure Metamorphic: Deep Continental Subduction. Geol Soc Am Spec Paper, 2006, 403: 45-77

52 董树文, 王小风，黄德志。大别山超高压变质带内浅变质岩片的发现及意义. 科学通报, 1996, 41(9): 815一820

53 Cliff R A. Isotopic dating in metamorphic belt. J Ged Soc London, 1985, 142: 97-110 $\underline{\text { [doi] }}$

54 Mezger K, Krogstad E J. Interpretation of discordant U-Pb zircon ages: A evaluation. J Metamorphic Geol, 1997, 15: 127-140[doi]

55 Liu Y C, Li S, Gu X, et al. Ultrhigh-pressure eclogite transformed from mafic granulite in the Dabie orogen. J Metamorph Geol, 2007, 25: $975-989$ [doi]

56 Li S, Huang F, Nie Y, et al. Geochemical and geochronological constrains on the suture location between the North and South China Blocks in the Dabie orogen, central China. Phys Chem Earth, 2001, 26: 655-672 [doi]

57 钟增球, 索书田, 张宏飞, 等。桐柏-大别碰撞造山带的基本组成与结构. 地球科学一中国地质大学学报, 2001, 26(6): $560-567$

58 Li X P, Zheng Y F, Wu Y B, et al. Low-T eclogite in the Dabie terrane of China: Petrological and isotopic constrains on fluid activity 
and radiometric dating. Contrib Mineral Petrol, 2004, 148: 443-470

59 Liu Y C, Li S, Xu S, et al. Geochemistry and geochronology of eclogites from the northern Dabie Mountains, central China. J Asian Earth Sci, 2005, 25: 431一 443 [doi]

60 李曙光, 刘德良, 陈移之, 等. 大别山南麓含柯石英榴辉岩的 Sm-Nd 同位素年龄. 科学通报, 1992, 37(4): 346一 349

61 Li S G, Xiao Y L, Liu D L, et al. Collision of the North China and Yangtze blocks and formation of coesite-bearing eclogites: Timing and processes. Chem Geol, 1993, 109: 89-111 [doi]

62 徐树桐，苏文，主贻灿，等。大别山北部榴辉岩的发现及其岩相学特征. 科学通报, 1999, 44(13): 1452-1456

63 刘贻灿, 徐树桐, 李曙光, 等. 大别山北部镁铁-超镁铁质岩带中榴辉岩的分布与变质温压条件. 地质学报, 2001, 75(3): 385-395

64 Tsai C H, Liou J G. Eclogite-facies relics and inferred ultrahigh-pressure metamorphism in the North Dabie Complex, central-eastern China. Am Mineral, 2000, 85: 1-8

65 徐树桐, 刘贻灿, 陈冠宝, 等. 大别山、苏鲁地区榴辉岩中新发现的微粒金刚石. 科学通报, 2003, 48(10): 1069-1075

66 Xu S T, Liu Y C, Chen G, et al. Microdiamonds, their classification and tectonic implications for the host eclogites from the Dabie and Su-Lu regions in central eastern China. Mineral Mag, 2005, 69: 509-520[doi]

67 Malaspina N, Hermann J, Scambelluri M, et al. Multistage metasomatism in ultrahigh-pressure mafic rocks from the North Dabie Complex (China). Lithos, 2006, 90: 19-42

68 刘贻灿, 李曙光, 徐树桐, 等. 大别山北部榴辉岩和英云闪长质片麻锆石 U-Pb 年龄及多期变质增生. 高校地质学报, 2000 , 6(3): $417-423$

69 谢智, 陈江峰, 张巽, 等. 大别造山带北部石竹河片麻岩的锆石 U-Pb 年龄及其地质意义. 岩石学报, 2001, 17: 139-144

70 葛宁洁, 夏群科, 吴元保, 等. 北大别燕子河片麻岩的锆石 U-Pb 年龄: 印支期变质事件的确定. 岩石学报, 2003, 19(3): $513-516$

71 薛怀民, 董树文, 刘晓春. 北大别大山坑二长花岗片麻岩的地球化学特征与锆石 U-Pb 年代学. 地球科学进展, 2003, 18(2): $192-197$

72 徐树桐, 刘贻灿, 江来利, 等. 大别山的构造格局和演化. 北京: 科学出版社, 1994

73 Cong B L. Ultrahigh-pressure Metamorphic Rocks in the Dabieshan-Sulu Region of China. Beijing: Science Press, 1996. 1-224

74 Castelli D, Rolfo F, Compagnoni R, et al. Metamorphic veins with kyanite, zoisite and omphacite in the Zhu-Jia-Chong eclogite Dabie Shan, China. Island Arc, 1998, 7: 159-173 $\underline{\text { [doi] }}$

75 Xiao Y L, Hoefs J, van den Kerkhof A M, et al. Geochemical constraints of the eclogite and granulite facies metamorphism as recognized in the Raobazhai complex from North Dabie Shan, China. J Metamorph Geol, 2001, 19: 3-19 [doi]

76 Xiao Y L, Hoefs J, van den Kerkhof A M, et al. Fluid history during HP and UHP metamorphism in Dabie Shan, China: Constraints from mineral chemistry, fluid inclusions, and stable isotopes. J Petrol, 2002, 43: 1505-1527 [doi]

77 刘贻灿, 徐树桐, 李曙光, 等. 大别山北部榴辉岩的大地构造属性及冷却史. 地球科学一中国地质大学学报, 2003, 28(1): $11-16$

78 刘贻灿, 徐树桐, 李曙光, 等. “罗田穹隆” 中的下地壳俯冲成因榴辉岩及其地质意义. 地球科学一一国地质大学学报, 2005, 30(1): $71-77$

79 Wang X M, Liou J G, Marruyama S. Coesite-bearing eclogites from the Dabie Mountains, central China: Petrogenesis, P-T path and implications for regional tectonics. J Geol, 1992, 100: 231-250

80 Okay A I. Petrology of diamond and coesite-bearing metamorphic terrane: Dabie Shan, China. Eur J Mineral, 1993, 5: 659-676

81 Zhai M G, Cong B L, Zhao Z Y, et al. Petrologic-tectonic units in the coesite-bearing metamorphic terrain of the Dabie Mountains, central China and their geotectonic implication. J SE Geosci, 1995, 11(1): 1-13

82 Rolfo F, Compagnoni R, Xu S, et al. First report of felsic whiteschist in the ultrahigh-pressure metamorphic belt of Dabie Shan, China. Eur J Mineral, 2000, 12: 883-898

83 Rolfo F, Compagnoni R, Wu W, et al. A coherent lithostratigraphic unit in the coesite-eclogite complex of Dabie Shan, China: Geologic and petrologic evidence. Lithos, 2004, 73: 71-94 [doi]

84 Okay A I, Sengör A M C. Tectonics of an ultrahigh-pressure metamorphic terrane: The Dabie Shan/Tongbai orogen, China. Tectonics, 1993, 12: 1320-1334 [doi]

85 Zartman R E. PIumbotectonics — the model. Tectonophysics, 1981, 75: 135-162[doi]

86 Zindler A, Hart S. Chemical geodynamics. Ann Rev Earth Planet Sci, 1986, 14: 493-571[doi]

87 张宏飞, 高山, 张本仁, 等. 大别山地壳结构的 $\mathrm{Pb}$ 同位素地球化学示踪. 地球化学, 2001, 30: 395-401

88 Li S G, Jagoutz E, Chen Y Z, et al. Sm-Nd and Rb-Sr isotope chronology of ultrahigh-pressure metamorphic rocks and their country 
rocks at Shuanghe in the Dabie Mountains, central China. GCA, 2000, 64: 1077-1093[doi]

89 Ames L, Zhou G, Xiong B. Geochronology and isotopic character of ultrahigh-pressure metamorphism with implications for the collision of the Sino-Korean and Yangtze cratons, central China. Tectonics, 1996, 15: 472-489 [doi]

90 李曙光, 李惠民, 陈移之, 等. 大别山-苏鲁地体超高压变质年代学— II. 锆石 U-Pb 同位素体系. 中国科学 D 辑: 地球科学, 1997, 27(3): 200-206

91 陈道公, Isachen C, 支霞臣，等. 安徽潜山片麻岩锆石 U-Pb 年龄. 科学通报, 2000, 45(2): 2110-2114

92 Ayers J C, Dunkle S, Gao S, et al. Constraints on timing of peak and retrograde metamorphism in the Dabie Shan ultrahigh-pressure metamorphic belt, east-central China, using U-Th-Pb dating of zircon and monazite. Chem Geol, 2002, 186: 315-331 [doi]

93 Wan Y S, Li R W, Wilde S A, et al. UHP metamorphism and exhumation of the Dabie Orogen, China: Evidence from SHRIMP dating of zircon and monazite from a UHP granitic gneiss cobble from the Hefei Basin. Geochim Cosmochim Acta, 2005, 69: 4333$4348 \underline{\text { doi }]}$

94 Liu D Y, Jian P, Kröner A, et al. Dating of prograde metamorphic events deciphered from episodic zircon growth in rocks of the Dabie-Sulu UHP complex, China. Earth Planet Sci Lett, 2006, 250: 650-666[doi]

95 Liu F L, Gerdes A, Liou J G, et al. SHRIMP U-Pb zircon dating from Sulu-Dabie dolomitic marble, eastern China: Constraints on prograde, ultrahigh-pressure and retrograde metamorphic ages. J Metamorph Geol, 2006, 24: 569-589

$96 \mathrm{Wu} \mathrm{Y} \mathrm{B}$, Zheng Y F, Zhao Z F, et al. U-Pb, Hf and O isotope evidence for two episodes of fluid-assisted zircon growth in marble-hosted eclogites from the Dabie orogen. Geochim Cosmochim Acta, 2006, 70: 3743-3761 [doi]

97 Wu Y B, Gao S, Zhang H, et al. Timing of UHP metamorphism in the Hong'an area, western Dabie Mountains, China: Evidence from zircon U-Pb age, trace element and Hf isotope composition. Contrib Mineral Petrol, 2008, 155: 123-133 [doi]

98 Zheng Y F, Gao T S, Wu Y B, et al. Fluid flow during exhumation of deeply subducted continental crust: Zircon U-Pb age and O-isotope studies of a quartz vein within ultrahigh-pressure eclogite. J Metamorphic Geol, 2007, 25: 267-283[doi]

99 李秋立, 李曙光, 侯振辉, 等. 青龙山榴辉岩高压变质新生锆石 SHRIMP U-Pb 定年、微量元素及矿物包裹体研究. 科学通报, 2004, 49(22): 2329-2334

100 Liu F L, Xu Z, Liou J G, et al. SHRIMP U-Pb ages of ultrahigh-pressure and retrograde metamorphism of gneisses, south-western Sulu terrane, eastern China. J Metamorph Geol, 2004, 22: 315-326[doi]

101 Li Q L, Li S G, Zheng Y F, et al. A high precision U-Pb age of metamorphic rutile in coesite-bearing eclogite from the Dabie Mountains in central China: A new constraint on the cooling history. Chem Geol, 2003, 200: 255-265[doi]

102 Li S G, Wang S S, Chen Y Z, et al. Wxcess argon in phengite from eclogite: Evidence from dating of eclogite minerals by Sm-Nd, $\mathrm{Rb}-\mathrm{Sr}$ and ${ }^{40} \mathrm{Ar} /{ }^{39} \mathrm{Ar}$ methods. Chem Geol, 1994, 112: 343-350[doi]

103 Yang J S, Wooden J L, Wu C L, et al. SHRIMP U-Pb dating of coesitebearing zircon from the ultrahigh-pressure metamorphic rocks, Sulu terrane, east China. J Metamorph Geol, 2003, 21: 551-560[10i]

$104 \mathrm{Li} \mathrm{J} \mathrm{Y,} \mathrm{Yang} \mathrm{T} \mathrm{N,} \mathrm{Chen} \mathrm{W,} \mathrm{et} \mathrm{al.}{ }^{40} \mathrm{Ar} /{ }^{39} \mathrm{Ar}$ dating of deformation events and reconstruction of exhumation of ultrahigh-pressure metamorphic rocks in Donghai, East China. Acta Geol Sin, 2003, 77: 155-168

105 Dong S W, Gao R, Cong B L, et al. Crustal structure of the Southern Dabie ultrahigh-pressure orogen and Yangtze foreland from deep seismic reflection profiling. Terra Nova, 2004, 16: 319-324 때oi]

106 董锋, 李曙光, 李秋立, 等. 中国大陆科学深钻 100 2000 m 超高压变质岩普通 $\mathrm{Pb}$ 同位素地球化学初步研究一俯冲陆壳内 脱耦的证据. 岩石学报, 2006, 22: 1791-1798

107 Xiao Y L, Zhang Z M, Hoefs J, et al. Ultrahigh-pressure metamorphic rocks from the Chinese Continental Scientific Drilling Project: II. Oxygen isotope and fluid inclusion distributions through vertical sections. Contrib Mineral Petrol, 2006, 152: 443-458 [doi]

108 Chen R X, Zheng Y F, Gong B, et al. Oxygen isotope geochemistry of ultrahigh-pressure metamorphic rocks from $200 \sim 4000$ m core samples of the Chinese Continental Scientific Drilling. Chem Geol, 2007, 242: 51-75[doi]

109 Meissner R, Mooney W. Weakness of the lower continental crust: A condition for delamination, uplift, and escape. Tectonophysics, 1998, 296: 47-60[doi]

110 Oxburgh E R. Flake tectonics and continental collision. Nature, 1972, 239: 202-204 [doi]

111 许靖华. 薄壳板块构造模式与冲撞型造山运动. 中国科学 A 辑, 1980, 23: 1081-1089

112 Gerya T V, Yuen D A, Maresh W V. Thermomechanical modeling of slab detachment. Earth Planet Sci Lett, 2004, 226: 101$116 \underline{\text { doi }]}$ 